\title{
Analisis Rencana Strategi Rumah Sakit Umum Daerah Arosuka, Kabupaten Solok
}

\author{
Efio Lasyera ${ }^{1}$, Yulia Hendri Yeni ${ }^{2}$, Hadril Busuddin ${ }^{3}$
}

\begin{abstract}
Abstrak
Rumah Sakit Umum Daerah Arosuka merupakan salah satu rumah sakit yang sejak tahun 2017 telah menerapkan Pola Pengelolaan Keuangan Badan Layanan Umum Daerah (PPK BLUD). Tujuan penelitian ini adalah mendapatkan perencanaan strategis yang tepat untuk pelayanan publik di Rumah Sakit Umum Daerah Arosuka. Penelitian ini merupakan studi deskriptif yang dilanjutkan dengan kualitatif. Analisis deskriptif menggunakan alat formulasi Matriks EFE, Matriks IFE, Matriks IE dan Matriks QSPM. Pengumpulan data dilakukan melalui data sekunder dalam periode waktu 5 tahun terakhir dan data primer melalui wawancara mendalam. Teknik yang digunakan untuk analisis data dan pengambilan keputusan melalui teknik Consensus Decision Making Group (CDMG). Hasil Penelitian didapatkan bahwa hasil analisis situasi dengan menggunakan Matriks IE berada di kuadran V maka Strategi yang paling baik dikendalikan di RSUD Arosuka adalah dengan strategi Hold and Maintain. Rekomendasi alternatif Strategi yang sesuai dengan positioning RSUD Arosuka adalah strategi Market Penetration (Penetrasi Pasar) dan Product Development (Pengembangan Produk). Dengan Matriks QSPM Prioritas Strategi terpilih untuk Renstra RSUD Arosuka 2017-2021 adalah meningkatkan mutu pelayanan, meningkatkan kompetensi SDM, meningkatan promosi/pemasaran luar gedung. Simpulan penelitian ini adalah perlunya meningkatkan mutu pelayanan dan kompetensi SDM serta promosi ke masyarakat Kabupaten Solok dan sekitarnya. Diperlukan komitmen yang kuat dari seluruh stock holder Rumah Sakit Umum Daerah Arosuka dalam pengimplementasian Renstra Rumah Sakit.
\end{abstract}

Kata Kunci: perencanaan strategis, rencana strategis

\section{Abstract}

Arosuka Regional Hospital is one of the Hospitals in Indonesia since 2012 has been implementing Financial Management Pattern of Regional Public Service Board (PPK BLUD). The objective of this study was to gain a plan strategic right business for public services at the Arosuka Regional Hospital.This study was a descriptive research, then support by qualitative research to approach the problem through descriptive analysis, using a formulation EFE Matrix, IFE Matrix, IE Matrix and QSPM Matrix. Data collected through secondary data within a period of 5 years and primary data through indepth interviews. The technique used for data analysis and decision-making is a technique Consensus Decision Making Group (CDMG). The Results showed that the analysis of the situation by using IE Matrix was in quadrant $V$, the best strategy is controlled in Arosuka Regional Hospitals with strategies hold and Maintain. Alternative recommendations in accordance with the positioning strategy is a strategy Arosuka Regional Hospital Market Penetration and Product Development. With QSPM Matrix selected Strategic Priorities for Business Strategic Plan 2017-2021 Arosuka Hospital was Improving Quality of Care, Improving Competence HR, Improving Promotion I Marketing outside the building. The conclusion of this study is the need to improve service quality and competence of human resources and promotion to Solok Regency and surrounding communities. The suggestions research is required strong commitment of all employees of the Arosuka Regional Hospital to implement strategic planning hospital business.

Keywords: strategic planning, strategic plan 
Affiliasi penulis: 1. Prodi S2 Kesehatan Masyarakat Fakultas Kedokteran Universitas Andalas Padang (FK Unand), 2. Fakultas Ekonomi Universitas Andalas 3. Direktur RS. Aisyiah Padang

Korespondensi: Efio Lasyera

E-mail: efiolasyeraanthony@yahoo.co.id HP. 08126696666

\section{PENDAHULUAN}

Pada proses manajemen, perencanaan sangat dibutuhkan oleh setiap organisasi dalam menjalankan kegiatannya. Perencanaan tersebut sebagai acuan organisasi untuk mencapai tujuan organisasi. Selain itu juga dapat membantu kita melakukan evaluasi secara berkala untuk menjamin tercapainya tujuan. ${ }^{1}$

Rumah Sakit harus mempunyai rencana strategis bisnis yang baik agar tujuan efisiensi, kemandirian dan pengembangan dalam organisasi dapat tercapai. Otonomi yang diberikan pada rumah sakit memberikan kesempatan untuk menyusun rencana bisnis yang visibel dalam bentuk rencana bisnis strategis. Perencanaan strategis membuat organisasi lebih proaktif dalam menentukan masa depan organisasi. Rencana strategis membantu organisasi merumuskan strategi yang lebih baik melalui pendekatan yang lebih sistematis, logis dan rasional. $^{2}$ Selain untuk tujuan efisiensi, kemandirian dan pengembangan, dengan perencanaan yang baik akan dapat meningkatkan kinerja Rumah Sakit secara keseluruhan. Hal ini sejalan dengan penelitian yang dilakukan oleh Nurhapna (2014) menyatakan bahwa perencanaan strategi bisnis berpengaruh terhadap kinerja rumah sakit. ${ }^{3}$

Rumah Sakit Umum Daerah (RSUD) Arosuka merupakan rumah sakit daerah di Kabupaten Solok yang didirikan sejak tahun 2007. RSUD Arosuka telah berstatus sebagai Rumah Sakit tipe C yang telah mampu memberikan pelayanan kedokteran subspesialis terbatas.

Dalam mendukung dan memberikan pelayanan tersebut serta melakukan pengembangan Rumah Sakit maka RSUD Arosuka telah menyusun 3 periode Rencana Strategi (Renstra) yaitu Renstra tahun 20072011, Renstra 2011-2015 dan Renstra 2016-2020. Namun dalam kurun waktu tersebut Rumah Sakit tidak mengalami peningkatan yang cukup signifikan pada indikator kinerja pelayanan, keuangan dan pengembangan pelayanan. ${ }^{4,5}$,
Wawancara dengan Direktur RSUD Arosuka, saat ini Rumah Sakit telah mempunyai dokumen perencanaan strategis dalam bentuk yang masih sangat sederhana, dimana hanya melakukan identifikasi faktor internal dan eksternal saja tanpa melakukan analisis lebih lanjut, sehingga belum tergambarkan posisioning organisasi dan pengembangan organisasi kedepan. Akibatnya dalam penyusunan Rencana Bisnis Anggaran dan Rencana Kegiatan Anggaran SKPD tiap tahunnya sering tidak berpedoman kepada Renstra yang ada karena tidak sesuai lagi dengan kebutuhan organisasi.

Berdasarkan observasi yang dilakukan peneliti dengan melakukan penelaahan pada tiga periode Renstra yaitu Renstra tahun 2007-2011, Renstra 2011-2015 dan Renstra 2016-2020 diketahui masih ditemukannya substansi pembahasan Renstra yang dicontoh dari tahun sebelumnya. Hal ini terlihat dari tidak adanya pembaharuan dalam analisis lingkungan yang meliputi isu internal dan eksternal di Rumah Sakit.

Hasil analisis terhadap Renstra RSUD Arosuka Kabupaten Solok diketahui bahwa faktor-faktor internal yang merupakan kelemahan dan berpengaruh terhadap kinerja RSUD Arosuka adalah masih kurangnya jumlah gedung pelayanan, masih kurangnya peralatan medis dan non medis, belum maksimalnya pemanfaatan sarana Instalasi Pengelolaan Air Limbah (IPAL), sebagaian besar dokter spesialis masih merupakan tenaga kontrak dan residen serta tidak tinggal di Kabupaten Solok, belum adanya tenaga Informasi dan Teknologi (IT), perekam medis belum terlatih, belum adanya Sistem Informasi Manajemen (SIM) RS serta billing system dan rekam medis masih dilakukan secara manual, kurangnya Promosi Rumah Sakit kepada masyarakat, sistem reward \& punishment dalam pembagian jasa belum terlaksana secara optimal, penerapan SPO Pelayanan belum berjalan maksimal dan komite medik serta komite keperawatan belum berperan secara optimal. Fenomena yang ada tersebut merupakan gambaran dari kurang optimalnya pemanfaatan Renstra RSUD Arosuka sehingga Rumah Sakit belum maksimal dalam melakukan pengembangan dan peningkatan kinerjanya. Berdasarkan latar belakang yang telah diuraikan diatas maka peneliti tertarik untuk 
melakukan penelitian yang berjudul Analisis Rencana

Strategi Rumah Sakit Umum Daerah Arosuka Kabupaten Solok.

\section{METODE}

Penelitian ini dilakukan dengan suatu rancangan penelitian deskriptif dan studi kebijakan (policy study) dengan metode kualitatif. Dari penelitian ini diharapkan dapat melakukan pendekatan masalah melalui analisis deskriptif, menggunakan alat formulasi Matriks EFE, Matriks IFE, Matriks IE dan QSPM dalam penetapan Rencana Strategi RSUD Arosuka Kabupaten Solok. Penelitian ini telah dilaksanakan di RSUD Arosuka Kabupaten Solok pada bulan Mei s/d Juni 2017.

\section{HASIL}

Didapatkan faktor eksternal yang menjadi peluang atau ancaman dan faktor internal yang menjadi kekuatan atau kelemahan. Analisis EFE menyimpulkan dan mengevaluasi hal-hal yang menyangkut peluang dan ancaman yang ada dalam lingkungan eksternal, digunakan matriks External Factor Evaluation (EFE) sedangkan IFE mengevaluasi faktor-faktor internal perusahaan yang berkaitan dengan kekuatan dan kelemahan yang dianggap penting, digunakan matriks Internal Factor Evaluation (IFE). Penilaian intuitif diperlukan dalam mengembangkan matriks EFE dan IFE. Penilaian matriks berdasarkan pemberian nilai bobot, rating dan skor melalui perkalian bobot dan rating. Bobot (weight) dari critical success factor tadi dengan skala yang lebih tinggi untuk yang berprestasi tinggi dan begitu pula sebaliknya. Jumlah seluruh bobot harus sebesar 1.0 baik pada matriks EFE dan juga IFE. Pemberian nilai bobot tersebut berdasarkan Consecus Decision Making Group (CDMG) antara peneliti dan pihak manajemen Rumah Sakit Umum Daerah Arosuka, nilai bobot berdasarkan penilaian intuisi terbaik (good intuitive judgment)/ subjektifitas CDMG.

\section{Hasil matriks Internal-Ekstenal (IE)}

Hasil IE Matrik berada di kuadran V maka strategi yang paling baik dikendalikan di RSUD Arosuka adalah dengan strategi-strategi Hold and
Maintain. Strategi yang umum dipakai yaitu strategi Market Penetration (Penetrasi Pasar) dan Product Development (Pengembangan Produk).

Berdasarkan hasil analisis IE Matriks, strategi yang tepat untuk Perencanaan Strategi Bisinis RSUD Arosuka tahun 2016-2021 adalah Product Development dan Market Penetration. Selanjutnya strategi terpilih dijabarkan menjadi beberapa strategi alternatif yang langsung dapat diimplimentasikan oleh RSUD Arosuka.

Peneliti mengajukan beberapa strategi alternatif yang dapat diimplementasikan untuk didiskusikan dan dianalisa dengan menggunakan Matriks QSPM. Strategi alternatif tersebut adalah sebagai berikut :

1. Strategi Product Development

a. Meningkatkan Mutu Pelayanan

b. Mengembangkan Jenis Pelayanan dan Produk Unggulan

c. Penambahan Sarana Prasarana Gedung

d. Penambahan Alat Medis

e. Meningkatkan Kompetensi SDM

2. Strategi Market Penetration

a. Meningkatan Promosi/Pemasaran luar gedung

b. Menjalin Kerjasama dengan Perusahaan/Badan Usaha/Asuransi lain

c. Membina dan membangun sistem jalur rujukan dengan Puskesmas, Praktek Dokter, Praktek Bidan, Klinik swasta dan Rumah Bersalin.

Secara umum strategi pengembangan produk adalah dengan cara meningkatkan penjualan dengan memperbaiki atau mengembangkan produk yang sudah ada. Dalam hal pelayanan rumah sakit, strategi pengembangan produk tentunya diarahkan pada pengembangan jenis pelayanan yang ada saat ini baik pengembangan dari sarana, jenis pelayanan yang diberikan maupun pengembangan kompetensi SDM. Strategi ini digunakan ketika sebuah organisasi memiliki produk yang berhasil/sukses dan telah berada pada tahap jenuh (maturity stage), pesaing menawarkan produk dengan kualitas lebih baik dan harga lebih murah, organisasi memiliki kemampuan riset dan pengembangan produk dan bersaing di industri yang sedang bertumbuh.

Strategi penetrasi pasar adalah meningkatkan pangsa pasar yang ada untuk produk tertentu melalui 
usaha pemasaran secara besar-besaran. Untuk strategi ini tentunya rumah sakit harus melakukan promosi secara intens dan berkesinambungan mengenai produk pelayanan yang tersedia, apa saja keunggulan yang bisa ditampilkan untuk menarik minat pasien dalam berkunjung, melakukan kerjasama dengan perusahaan asuransi, badan usaha dan organisasi lain dalam pelayanan rujukan dan lain sebagainya. Tentunya proses promosi berupa media elektronik dan media cetak terus dilakukan secara kontinyu baik melalui leaflet, brosur, baliho, penyampaian informasi di radio dan lainnya. Promosi ini dilakukan dengan bahasa yang menarik dan mudah dipahami oleh masyarakat sehingga muncul keinginan dari masyarakat untuk melakukan pelayanan di rumah sakit tersebut.

Terdapat hubungan yang tinggi antara pengeluaran untuk pemasaran terhadap kenaikan penjualan, pangsa pasar pesaing menurun sedangkan total penjualan industri meningkat dan pasar yang ada belum jenuh oleh produk dan jasa perusahaan. ${ }^{5}$ Ini berarti rumah sakit harus melakukan perencanaan matang dan penganggaran yang cukup untuk kegiatan promosi tersebut.

Hasil penelitian ini diharapkan sebagai langkah awal dalam pembuatan Perencanaan Strategis Bisnis Rumah Sakit Umum Daerah Arosuka yang sesungguhnya. Berdasarkan hasil penelitian maka direkomendasikan Rencana Strategis Bisnis untuk periode tahun 2017-2021 adalah sebagai berikut:

\section{Visi dan Misi}

Berdasarkan hasil analisis eksternal dan internal, didapatkan beberapa alternative strategi yang sebaiknya dilakukan oleh RSUD Arosuka. Selain itu Visi dan Misi yang ada saat ini perlu dipertajam agar tujuan dan sasaran serta kebijakan yang akan dilakukan dapat lebih konkrit.

Adapun Visi RSUD Arosuka untuk periode tahun 2017-2021 yang diusulkan adalah "Menjadi Rumah Sakit Pilihan Utama Masyarakat di wilayah Kabupaten Solok". Visi tersebut dirasakan cukup visible dan dapat diraih oleh rumah sakit. Sedangkan misinya adalah sebagai berikut : a. Memberikan pelayanan yang bermutu dan berorientasi kepada keselamatan pasien dan kepuasan pasien.

b. Menciptakan Sumber Daya Manusia yang berkompeten melalui pengembangan Sumber Daya Manusia secara komprehensif

c. Meningkatkan program pelayanan medik dan mengembangkan pelayanan unggulan.

d. Mengembangkan program promosi Rumah Sakit dan membangun kemitraan dengan jejaring pelayanan kesehatan.

\section{Misi, Tujuan dan Sasaran RSUD Arosuka}

MISI 1

Memberikan pelayanan yang bermutu dan berorientasi kepada keselamatan pasien dan kepuasan pasien.

1. Mewujudkan pemberian pelayanan yang bermutu dan sesuai standar.

2. Mewujudkan pelayanan yang berorientasi kepada keselamatan pasien dan kepuasan pasien.

3. Meningkatnya kualitas dan kuantitas pelayanan RS.

4. Terwujudnya pelayanan yang sesuai standar operasional prosedur yang ada

\section{MISI 2}

Menciptakan Sumber Daya Manusia yang berkompeten melalui pengembangan Sumber Daya Manusia secara komprehensif

1. Mengembangkan kompetensi Sumber Daya Manusia dalam memberikan pelayanan kesehatan melalui pendidikan dan pelatihan secara berkesinambungan

2. Terlaksananya kegiatan pengembangan kompetensi SDM secara merata dan berkesinambungan

\section{MISI 3}

Meningkatkan program pelayanan medik dan mengembangkan pelayanan unggulan.

1. Mengembangkan pelayanan medik dan pelayanan unggulan dengan melengkapi sarana dan prasarana penunjang pelayanan 
2. Terlaksananya pengembangan Pelayanan dan produk unggulan

3. Terpenuhinya kebutuhan sarana prasarana Gedung dan alat medis sesuai dengan standar kebutuhan RS kelas $C$

4. Terpeliharanya sarana dan prasarana yang telah tersedia

\section{MISI 4}

Mengembangkan program promosi Rumah Sakit dan membangun kemitraan dengan jejaring pelayanan kesehatan

1. Meningkatkan program promosi rumah sakit dengan memanfaatkan teknologi informasi

2. Menjalin kemitraan dengan jejaring pelayanan kesehatan lain didalam dan luar wilayah

3.Terlaksananya kerjasama antar lembaga, perusahaan, badan usaha

4. Meningkatnya jejaring pelayanan dalam sistem rujukan

5. Meningkatnya pangsa pasar rumah sakit.

6. Terlaksananya pengelolaan manajemen yang efektif dan efisien.

Berdasarkan tujuan RSUD Arosuka yang telah dijabarkan sebelumnya, maka dapat disusun strategi dan kebijakan sebagai berikut :

\section{Strategi dan Kebijakan RSUD Arosuka}

Mewujudkan pemberian pelayanan yang bermutu dan sesuai standar. Meningkatkan kualitas dan kuantitas pelayanan RSMelakukan pelayanan sesuai standar RS tipe C. Mewujudkan pelayanan yang berorientasi kepada keselamatan pasien dan kepuasan pasien. Penyusunan SPO pelayanan dan mensosialisasikan kepada seluruh petugas.

Penyusunan tim khusus perumusan serta sosialisasi SPO pelayanan dan keselamatan pasien. Mengembangkan kompetensi Sumber Daya Manusia dalam memberikan pelayanan kesehatan melalui pendidikan dan pelatihan secara berkesinambungan. Meningkatkan profesionalisme SDM sesuai standar kompetensi Menyusun program Peningkatan kompetensi SDM secara rutin sesuai kebutuhan RSUD. Mengembangkan pelayanan medik dan pelayanan unggulan dengan melengkapi sarana dan prasarana penunjang pelayanan.
Penyusunan perencanaan pelayanan unggulan RSUD Menyusun tim khusus dalam rangka menganalisis dan menyusun perencanaan SDM, kebutuhan sarana prasarana dan teknis pelaksanaan pelayanan unggulan. Meningkatkan program promosi rumah sakit dengan memanfaatkan teknologi informasi. Menyusun program pengembangan promosi RS yang berbasis teknologi informasi. Melakukan promosi RS dengan pemanfaatan media teknologi informasi. Menjalin kemitraan dengan jejaring pelayanan kesehatan lain didalam dan luar wilayah. Meningkatkan pangsa pasar RS dengan melaksanakan pengelolaan manajemen yang efektif dan efisien Menjalin kerjasama dengan perusahaan, badan usaha dan asuransi lainnya (MoU kerjasama pelayanan kesehatan).

\section{Program}

Program merupakan suatu upaya untuk dapat mengimplementasikan strategi serta proses penentuan jumlah dan jenis kegiatan yang diperlukan dalam rangka pelaksanaan suatu perencanaan. Program berisikan tentang kegiatan yang berorientasi pada hasil yang ingin dicapai selama kurun waktu 1 (satu) sampai dengan 5 (lima) tahun ke depan dengan mempertimbangkan kekuatan, kelemahan, peluang dan ancaman yang dihadapi atau mungkin timbul. Maka disusun program Rumah Sakit Umum Daerah Arosuka sebagai berikut :

1. Peningkatan Mutu Pelayanan

2. Pengadaan, peningkatan sarana dan prasarana rumah sakit

3. Pemeliharaan sarana prasarana rumah sakit

4. Pengembangan SDM

5. Pengembangan pelayanan dan produk unggulan

6. Peningkatan promosi kepada pihak internal dan eksternal

7. Pengembangan Jejaring Rujukan dan kerjasama antar lembaga dan perusahaan

8. Pelayanan administrasi Perkantoran

\section{PEMBAHASAN}

Hasil penelitian ini menunjukan bahwa analisis terhadap faktor eksternal setelah dihitung dengan EFE Matriks berjumlah 2,886 mengindikasikan bahwa RSUD Arosuka merespon dengan baik terhadap 
peluang-peluang yang ada dan menghindari ancamanancaman dari lingkungan luar rumah sakit. Sedangkan analisis terhadap faktor internal setelah dihitung dengan IFE Matriks berjumlah 2,500 mengindikasikan bahwa kondisi internal rumah sakit adalah rata-rata.

Berdasarkan hasil analisis situasi dengan menggunakan IE Matrik berada di kuadran $\mathrm{V}$ maka Strategi yang paling baik dikendalikan di RSUD Arosuka adalah dengan strategi-strategi hold and Maintain. Rekomendasi alternatif Strategi yang sesuai dengan positioning RSUD Arosuka adalah strategi Market Penetration (Penetrasi Pasar) dan Product Development (Pengembangan Produk). Strategi terpilih untuk Renstra RSUD Arosuka 2017-2021 adalah dengan meningkatkan kualitas dan kuantitas pelayanan RS,SOP yang standar,profesionalisme SDM, plan dan program akuntabel berbasis IT serta meningkatkan pangsa pasar RS dengan melaksanakan pengelolaan manajemen yang efektif dan efisien.

\section{SIMPULAN}

Diperlukan peningkatkan mutu pelayanan dan kompetensi SDM serta promosi ke masyarakat Kabupaten Solok dan sekitarnya.

\section{DAFTAR PUSTAKA}

1. Dadang S. Sistem, proses, mekanisme, dan dokumen perencanaan pembangunan nasional sesuai UU25/2004. Jakarta: Badiklat Depdagri Diklat Perencanaan dan Evaluasi Kinerja Program Pembangunan Jakarta; 2008.

2. David FR. Manajemen strategis: konsep. Edisi ke12. Paulyn ,S, Harryadin, M,Stefanus, R, editors penterjemah. Jakarta: Penerbit Salemba Empat; 2009.

3. Nurhapna. Pengaruh perencanaan strategis terhadap kinerja di rumah sakit. Jurnal Administrasi Kesehatan Indonesia. 2014; 2(2).

4. Rumah Sakit Umum Daerah Arosuka. Rencana strategi bisnis 2011-2015. Solok: RSUD Arosuka; 2007.

5. Alimudin A. Manajemen strategis. Surabaya: Universitas Narotama; 2004 